\title{
Thermodynamic constraints on effective energy and mass transfer and catchment function
}

\author{
C. Rasmussen \\ Department of Soil, Water and Environmental Science, The University of Arizona, 1177 E. Fourth Street, P.O. Box 210038, \\ Tucson, AZ 85721, USA
}

Correspondence to: C. Rasmussen (crasmuss@ cals.arizona.edu)

Received: 12 July 2011 - Published in Hydrol. Earth Syst. Sci. Discuss.: 26 July 2011

Revised: 16 November 2011 - Accepted: 24 February 2012 - Published: 6 March 2012

\begin{abstract}
Understanding how water, energy and carbon are partitioned to primary production and effective precipitation is central to quantifying the limits on critical zone evolution. Recent work suggests quantifying energetic transfers to the critical zone in the form of effective precipitation and primary production provides a first order approximation of critical zone process and structural organization. However, explicit linkage of this effective energy and mass transfer (EEMT; $\mathrm{W} \mathrm{m}^{-2}$ ) to critical zone state variables and well defined physical limits remains to be developed. The objective of this work was to place EEMT in the context of thermodynamic state variables of temperature and vapor pressure deficit, with explicit definition of EEMT physical limits using a global climate dataset. The relation of EEMT to empirical measures of catchment function was also examined using a subset of the Model Parameter Estimation Experiment (MOPEX) catchments. The data demonstrated three physical limits for EEMT: (i) an absolute vapor pressure deficit threshold of $1200 \mathrm{~Pa}$ above which EEMT is zero; (ii) a temperature dependent vapor pressure deficit limit following the saturated vapor pressure function up to a temperature of $292 \mathrm{~K}$; and (iii) a minimum precipitation threshold required from EEMT production at temperatures greater than $292 \mathrm{~K}$. Within these limits, EEMT scales directly with precipitation, with increasing conversion of the precipitation to EEMT with increasing temperature. The state-space framework derived here presents a simplified framework with well-defined physical limits that has the potential for directly integrating regional to pedon scale heterogeneity in effective energy and mass transfer relative to critical zone structure and function within a common thermodynamic framework.
\end{abstract}

\section{Introduction}

Understanding how water, energy and carbon are partitioned to evaporation, primary production, runoff and base-flow is central to quantifying the limits on critical zone function and evolution, and represent grand challenges to the Earth Science community (NRC, 2010; Sivapalan, 2005). The critical zone, defined as the Earth surface system extending from the top of vegetation down to and including groundwater, sustains and enables life on the planet (NRC, 2001). The importance of coupled water-energy-carbon dynamics to understanding critical zone function is well recognized across Earth science disciplines (Berry et al., 2005; Brantley et al., 2011; Minasny et al., 2008; Schimel et al., 1997). Recent work suggests that quantifying the energetic transfer associated water, energy and carbon transfers to the critical zone in the form of effective precipitation and primary production provides a first order approximation of critical zone process and structural organization (Rasmussen et al., 2011b). This work found significant empirical correlations of these energy and mass transfers to critical zone properties and processes. However, explicit linkage of these empirical relations to critical zone state variables and well defined physical limits on primary production and evapotranspiration remains to be developed.

The critical zone functions as an open system relative to energy and matter fluxes in the form of water, carbon and radiation. Open system thermodynamics and its focus on movement of energy and mass across gradients thus present a promising framework within which to quantify the physical limits of critical zone process and evolution. Open system 


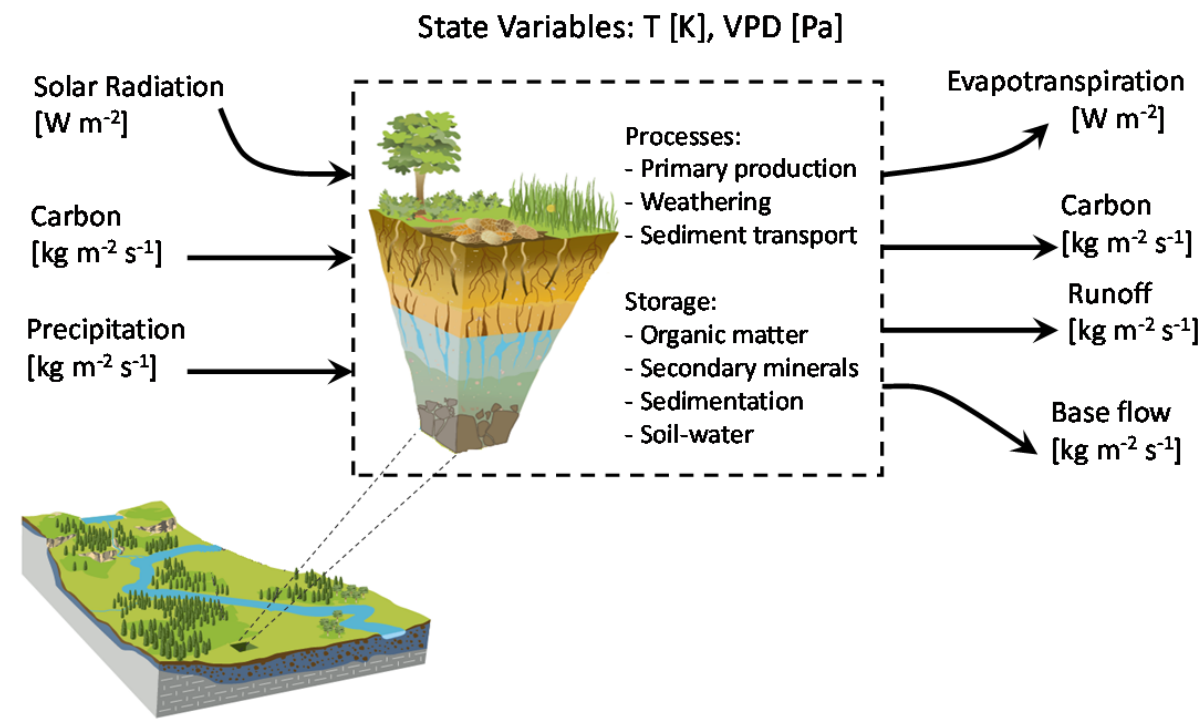

Fig. 1. Conceptual diagram of the critical zone as an open thermodynamic system described by the state variables of temperature $(T)$ and vapor pressure deficit (VPD), and energy and mass flux terms deriving from solar radiation, precipitation, and carbon input as primary production. The energy and mass transfer drives internal critical zone processes, change and storage of internal energy and mass, and export of dissipative products in the form of evapotranspiration, carbon from plant and microbial respiration and runoff and baseflow. Note that geophysical energy and mass transfers associated with tectonics and denudation are not included here. Modified from Rasmussen et al. (2011b).

thermodynamic principles have been applied broadly across the Earth sciences to understand and model the movement of energy and mass through various components of the Earth system including: turbulent flows in the atmosphere (Ozawa et al., 2003), the global hydrologic cycle (Kleidon, 2009), stream network organization (Rinaldo et al., 1998), ecological interactions and ecosystem development (Jørgensen and Fath, 2004; Odum, 1988), physical and biological controls on landscape evolution (Phillips, 2009), pedogenesis (Smeck et al., 1983; Volobuyev, 1983), and the movement of soilwater along preferential flow paths (Zehe et al., 2010). Similar to engineered systems (Bejan, 2006), it is posited that gradient driven fluxes of energy and mass through the critical zone drive the development of subsurface process and structural organization, such as preferential soil hydrologic flow paths, with a selection for those paths that maintain the strongest gradients. The coupled process and structural organization serves to optimize the cycling and degradation of work energy associated with the energy and mass fluxes flowing through the critical zone system (Lin, 2010; Schneider and Kay, 1994; Odum, 1988).

In a series of papers, Rasmussen et al. presented a coupled energy and mass transfer term referred to as "effective energy and mass transfer" (EEMT) that couples energy and mass flux to the subsurface in the form of effective precipitation and net primary production in a common energy unit [W m ${ }^{-2}$ ] (Rasmussen et al., 2005, 2011b; Rasmussen and Tabor, 2007). The EEMT parameter exhibits strong and significant correlation to a variety of measures of critical zone structure and function, including chemical weathering rates, soil depth, classification and geochemistry, and ecosystem respiration. The objective of this work is to place these empiricisms into a well-defined thermodynamic context of physical state-space. Specifically, effective energy and mass transfer is placed in the context of the state variables temperature and vapor pressure deficit, and physical limits defined for the partitioning of energy, water, and carbon to EEMT. Furthermore, the relation of EEMT to empirical measures of catchment function is examined using a subset of the MOPEX watersheds.

\section{Materials and methods}

\subsection{Theoretical construct - thermodynamic framework}

The critical zone operates as an open system with respect to energy and mass fluxes that include solar radiation, water, carbon, and sediment (Fig. 1). These fluxes drive internal critical zone processes such as primary production, chemical weathering, mineral transformation, and sediment transport. The processes manifest changes in critical zone energy and mass in the form of stored organic matter, secondary minerals, and sedimentation, among others. The products of critical zone processes include energy and mass flux associated with evapotranspiration, respiration, and chemical denudation that may be exported from the critical zone system. Exported energy and mass represent dissipative products 
equivalent to entropy production and export in a thermodynamic context. Critical zone function may thus be characterized using principles of energy and mass balance within an open system thermodynamic framework (e.g., Kleidon, 2010).

In a thermodynamic framework, state variables are used to define the system state, or the ensemble of thermodynamic properties, such as internal energy and entropy, at a given point in time (Bejan, 2006). State variables include quantities that are independent of system size, internal energy, and internal processes, and may be used to place physical constraints on the change in system state. In the strictest sense, thermodynamic systems with a given set of state variables and rates of energy and mass transfer will converge to the same ensemble of thermodynamic properties, regardless of the path or suite of internal processes (Anderson, 2005). Common thermodynamic state variables include temperature and pressure, parameters directly applicable to defining critical zone energy and mass transfer. Indeed, Montieth's (1965) modification of Penman's (1948) equation for evaporation from a saturated surface used a thermodynamic state-space approach, with vapor pressure and temperature as state variables, to include evaporation for dry surfaces removed from the saturated vapor pressure-temperature state function. Vapor pressure deficit, temperature, and partial pressure of atmosphere $\mathrm{CO}_{2}$ exert strong control on the physical and biological processes of evaporation and transpiration (Jarvis and McNaughton, 1986), primary production (Running and Coughlan, 1988), and chemical weathering rates (Rasmussen et al., 2011a). For practical purposes, it may be assumed that $p \mathrm{CO}_{2}$ is constant such that in the context of the critical zone as a thermodynamic system presented here, vapor pressure deficit and temperature may be defined as the system state variables.

As noted, the dominant energy and mass transfers to the critical zone include solar radiation, water, carbon, and sediment supply and transport. In a generalized form, this may be expressed as:

$\mathrm{CZ}=f\left(T, \mathrm{VPD}, \mathrm{PPT}, R_{\mathrm{n}}, \mathrm{CO}_{2}, S, t_{\mathrm{r}}\right), \quad\left[\mathrm{J} \mathrm{m}^{-2}\right]$

where $\mathrm{CZ}$ is critical zone state quantified in terms of energy per area, $T$ temperature [K], VPD vapor pressure deficit [Pa], PPT precipitation $\left[\mathrm{kg} \mathrm{m}^{-2} \mathrm{~s}^{-1}\right], R_{\mathrm{n}}$ net solar radiation $\left[\mathrm{W} \mathrm{m}^{-2}\right], \mathrm{CO}_{2}$ carbon dioxide $\left[\mathrm{kg} \mathrm{m}^{-2} \mathrm{~s}^{-1}\right], S$ is mineral supply/sediment transport $\left[\mathrm{kg} \mathrm{m}^{-2} \mathrm{~s}^{-1}\right]$, and $t_{\mathrm{r}}$ is the relative age of the system [s]. Thus, for a given temperature and vapor pressure deficit state-space, the function and state of the critical zone may be directly related to fluxes of water, radiation, carbon, and sediment. This equation is essentially a restatement of the classic "state-factor" statement proposed by Jenny (1941) for characterizing the state of soil systems, and similar to other state-factor approaches defining critical zone evolution and process (e.g., Phillips, 1998; Hugget, 1995; Pope et al., 1995).

\subsection{Theoretical construct - energy and mass balance}

The flux, storage, and export of critical zone energy and mass components may be characterized using balance equations for the dominant energy (net radiation), water (precipitation) and carbon (primary production) fluxes. The balance equation for net radiation $\left(R_{\mathrm{n}}\right)$ may be stated as (Berry et al., 2005): $R_{\mathrm{n}}=\lambda \mathrm{ET}+H+G+A+\mathrm{AE}\left[\mathrm{W} \mathrm{m}^{-2}\right]$, where $\lambda$ is latent heat of vaporization, ET is evapotranspiration rate, $H$ the sensible heat flux, $G$ the heat flux into the soil, $A$ the flux of energy into chemical bonds formed during photosynthesis and stored in the form of reduced organic compounds, and $\mathrm{AE}$ is advected energy. Over annual time scales and for a given location $\mathrm{AE}$ and $G$ approach zero, and in general, $A$ is only a fraction of $R_{\mathrm{n}}$ and typically ignored in most soil and hydrologic applications. Note that advected energy and soil heat flux may perform important physical work on subsurface soil systems through volumetric changes resulting from freeze-thaw processes. These are not directly considered here. The transfer of energy to reduced organic compounds represents a central energetic flux in terms of subsurface critical zone development (Amundson et al., 2007) and is thus central to the framework discussed herein.

The critical zone water balance may be expressed following the catchment scale approach of L'vovich (1979): $W=\mathrm{PPT}-\mathrm{SR}=\mathrm{ET}+F+\mathrm{BIO}\left[\mathrm{kg} \mathrm{m}^{-2} \mathrm{~s}^{-1}\right]$, where $W$ is subsurface or catchment wetting, PPT is precipitation, SR is quick runoff, ET is mass of water returned to the atmosphere by evapotranspiration, $F$ is mass flux to base flow and equivalent to the fraction of precipitation available to flux through the soil and participate in weathering processes and solute transport, and BIO is the mass of water incorporated into biomass via primary production.

Energy and water cycles are directly coupled via photosynthesis and primary production (Campbell and Norman, 2000): $6 \mathrm{CO}_{2}+6 \mathrm{H}_{2} \mathrm{O} \stackrel{\leftrightarrow}{A} \mathrm{C}_{6} \mathrm{H}_{12} \mathrm{O}_{6}+6 \mathrm{O}_{2}$, where atmospheric $\mathrm{CO}_{2}$ and water sourced from the critical zone, equivalent to the BIO fraction of the water balance, are coupled via photosynthesis powered by solar radiation, equivalent to $A$ from the net radiation balance, to produce energyrich reduced organic compounds. Primary production essentially represents a conversion of radiative energy to chemical energy stored in $\mathrm{C}-\mathrm{C}$ and $\mathrm{C}-\mathrm{H}$ bonds of organic compounds (Berry et al., 2005). Carbon assimilation into organic compounds by photosynthesis is coupled with substantial loss of water via transpiration, with approximately $90 \%$ of water adsorbed by roots transpired to the atmosphere (Raven et al., 1971). The relative water use efficiency, defined as the ratio of carbon assimilation to transpiration, may be expressed directly as a function of intra-leaf and atmospheric $\mathrm{CO}_{2}$ concentrations and vapor pressure deficit, with increased partitioning of water to transpiration with increasing vapor pressure deficits (Comstock and Ehleringer, 1992). Primary production is thus a central process linking the flux of water, energy, and carbon into and through the critical zone, and 
is strongly controlled by the state variable of vapor pressure deficit. Assimilation is also coupled with substantial loss of $\mathrm{CO}_{2}$ back to the atmosphere, on the order of $50 \%$, as a result of plant metabolic processes (Farrar, 1985). Net primary production $\left[\mathrm{kg} \mathrm{m}^{-2} \mathrm{~s}^{-1}\right]$ is the balance of gross primary production and plant respiration, and thus represents the net transfer of photosynthetic chemical energy into the critical zone (Lovett et al., 2006). It should be noted that nutrients, such as $N$ and $P$, can significantly limit primary production in areas with otherwise sufficient water and radiation (e.g., Melillo et al., 1993). For simplicity, the analysis here does not take nutrient limitation into account.

Based on these balance equations, Rasmussen et al. (2011b) derived a coupled energy, water, and carbon balance for the critical zone that in simplified form equates to:

$\mathrm{EEMT}=E_{\mathrm{PPT}}+E_{\mathrm{BIO}}\left[\mathrm{W} \mathrm{m}^{-2}\right]$

where EEMT is the total "effective energy and mass transfer" into the critical zone and represents energy that can perform work on the subsurface, $E_{\mathrm{PPT}}$ is the energy flux associated with effective precipitation, and $E_{\mathrm{BIO}}$ is the energy flux from net primary production. The individual terms of Eq. (2) may be quantified in units of $\mathrm{W} \mathrm{m}^{-2}$ as $E_{\mathrm{PPT}}=F \cdot c_{\mathrm{w}} \cdot \Delta T$, where $F$ is mass flux of precipitation to base flow $\left[\mathrm{kg} \mathrm{m}^{-2} \mathrm{~s}^{-1}\right], c_{\mathrm{W}}$ is specific heat of water $\left[\mathrm{J} \mathrm{kg}^{-1} \mathrm{~K}^{-1}\right]$, and $\Delta T=T_{\text {ambient }}-T_{\text {ref }}[\mathrm{K}]$ with $T_{\text {ambient }}$ the ambient temperature at time of water flux and $T_{\text {ref }}$ set at $273.15 \mathrm{~K}$; and $E_{\mathrm{BIO}}=\mathrm{NPP} \cdot h_{\mathrm{BIO}}$, where NPP is mass flux of carbon as net primary production $\left[\mathrm{kg} \mathrm{m}^{-2} \mathrm{~s}^{-1}\right]$, and $h_{\mathrm{BIO}}$ the specific biomass enthalpy $\left[\mathrm{J} \mathrm{kg}^{-1}\right]$ assumed here to be $22 \times 10^{6} \mathrm{~J} \mathrm{~kg}^{-1}$.

The formulation of EEMT does not include important geophysical energy inputs, e.g., tectonics, isostasy, and gravity driven mass flows. A complete critical zone energy balance must include these components to properly account for physical and chemical weathering, and the transfer of sediment associated with tectonic uplift and gravitational forces (Phillips, 2009; Volobuyev, 1964; Odum, 1988). In systems of rapid tectonic uplift and limited energy and mass transfer from precipitation and biological production, geophysical fluxes may dominate critical zone energy and mass flows. However, for many systems the geophysical fluxes can be orders of magnitude less than $E_{\mathrm{PPT}}$ and $E_{\mathrm{BIO}}$ (Rasmussen et al., 2011b). Furthermore, given that the energy associated with evapotranspiration is returned back to the atmosphere, $E_{\mathrm{PPT}}$ and $E_{\mathrm{BIO}}$ can represent the primary sources of energy transferred to the subsurface critical zone system. Thus for simplicity, the presentation here focuses on energy and mass fluxes associated with effective precipitation and net primary production. The sum of $E_{\mathrm{PPT}}$ and $E_{\mathrm{BIO}}$ is termed "effective energy and mass transfer" (EEMT) to recognize that this flux represents the effective chemical and heat energy available to perform work on the subsurface system.
The production of EEMT may be expressed in a generalized state-factor form as:

EEMT $=f\left(T, \mathrm{VPD}, \mathrm{PPT}, R_{\mathrm{n}}, \mathrm{CO}_{2}\right),\left[\mathrm{W} \mathrm{m}^{-2}\right]$

similar to the general statement of factors controlling evaporation put forth by Jarvis and McNaughton (1986). For simplicity and ignoring the effects of changed EEMT rates on net radiation and $\mathrm{CO}_{2}$ uptake, the total differential of Eq. (3) yields:

$$
\begin{aligned}
\mathrm{dEEMT} & =\left(\frac{\partial \mathrm{EEMT}}{\partial \mathrm{VPD}}\right)_{T, \mathrm{PPT}} \mathrm{dVPD}+\left(\frac{\partial \mathrm{EEMT}}{\partial T}\right)_{\mathrm{VDP}, \mathrm{PPT}} \mathrm{d} T \\
& +\left(\frac{\partial \mathrm{EEMT}}{\partial \mathrm{PPT}}\right)_{T, \mathrm{VPD}} \mathrm{dPPT} .
\end{aligned}
$$

As noted, the variables VPD and $T$ represent state variables independent of the system such that for a given VPD$T$ space, EEMT may be stated as a direct function of PPT where: $\quad$ dEEMT $=\left(\frac{\partial \text { EEMT }}{\partial \mathrm{PPT}}\right)_{\mathrm{VPD}, T}$ dPPT. Here we explicitly define this function for a range of temperature and vapor pressure deficit space and thereby define the physical statespace for EEMT production.

\subsection{Data and methods}

The analysis here is based on average monthly climate data from 314 meteorological stations distributed across nearly all latitudes and longitudes as compiled by the IAEA's Water Resource Program and the World Meteorological Organization in the Global Network of Isotopes in Precipitation (GNIP) database (IAEA/WMO, 2006). Meteorological data in the GNIP database include average monthly precipitation, temperature and vapor pressure with a median observation record of 14 years for each station and $10 \%$ and $90 \%$ quantiles of 4 and 38 years, respectively.

The calculation of $E_{\mathrm{PPT}}$ and $E_{\mathrm{BIO}}$ were based on the balance of precipitation and evapotranspiration following Rasmussen and Tabor (2007). Given the lack of site specific water balance data, the base-flow, or $F$, term for calculating $E_{\mathrm{PPT}}$ was approximated using an effective precipitation term: $P_{\text {eff }}=$ PPT - PET $\left[\mathrm{kg} \mathrm{m}^{-2} \mathrm{~s}^{-1}\right]$, where PET is potential evapotranspiration. This method of calculating $P_{\text {eff }}$ does not account for months with precipitation and actual ET is less than PET or for moisture carry-over in the form of soil moisture storage and thus only provides an approximation of the total effective precipitation for a given location. Monthly PET was calculated using the Thornthwaite and Mather (1957) approach that uses a minimal site specific dataset of temperature and latitude to approximate surface energy budget and provides a simple and meaningful approximation of PET for global scale climate characterization (Black, 2007).

Biological energy flux derived from net primary production (NPP) was calculated following Rasmussen et al. (2005) using a modified form of the sigmoid equation 
of Lieth (1975) relating NPP to mean annual temperature: $\mathrm{NPP}=3000\left[1+e^{1.315-0.119 T}\right]^{-1}\left[\mathrm{~g} \mathrm{~m}^{-2} \mathrm{yr}^{-1}\right]$. Using this equation, NPP was calculated on a monthly time step for all months of PPT $>$ PET, and NPP scaled to a monthly time step based on each months percentage of one year (i.e.,

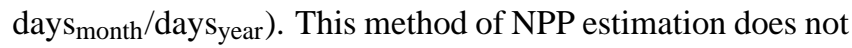
account for primary production that occurs using stored soil moisture and thus likely underestimates total NPP. However, comparison of NPP calculated using this method relative to global NPP datasets indicates good agreement between the two (Rasmussen et al., 2005). As noted previously, $E_{\mathrm{BIO}}$ was calculated as NPP times an average specific enthalpy for organic materials of $22 \times 10^{6} \mathrm{~J} \mathrm{~kg}^{-1}$.

Vapor pressure deficit was calculated as: $\mathrm{VPD}=e_{\mathrm{s}}-e$ [Pa], where $e_{\mathrm{S}}$ is saturated vapor pressure, and $e$ is vapor pressure as reported in the GNIP dataset. Saturated vapor pressure was calculated using a form of the Clausius-Clapeyron equation that defines the change in saturated vapor pressure per unit temperature:

$e_{\mathrm{S}}=e_{\mathrm{o}} \exp \left[\frac{L_{\mathrm{V}}}{R_{\mathrm{V}}}\left(\frac{1}{T_{\mathrm{O}}}-\frac{1}{T}\right)\right], \quad[\mathrm{Pa}]$

where $e_{\mathrm{o}}$ of $611.73 \mathrm{~Pa}$ is the reference saturated vapor pressure at $T_{\mathrm{O}}$ of $273.16 \mathrm{~K}, L_{\mathrm{V}}$ is latent heat of vaporization at $T_{\mathrm{o}}\left[2.501 \times 10^{6} \mathrm{~J} \mathrm{~kg}^{-1}\right]$, and $R_{\mathrm{V}}$ is the gas constant for moist air $\left[461.50 \mathrm{~J} \mathrm{~K}^{-1} \mathrm{~kg}^{-1}\right]$. It was assumed that $L_{\mathrm{V}}$ is constant with temperature and the small decrease in $L_{\mathrm{V}}$ with increasing temperature was not accounted for (Iribarne and Godson, 1981).

The data analysis here focused on monthly time scales. The monthly data were subset to exclude stations with any missing meteorological data and locations where monthly VPD was less than zero for a total $n=2276$. Monthly $E_{\mathrm{PPT}}$, $E_{\mathrm{BIO}}$, and EEMT data were scaled to $\mathrm{W} \mathrm{m}^{-2}$.

\subsection{MOPEX data analysis}

Data from eighty-six of the eighty-nine MOPEX dataset catchments analyzed by Troch et al. (2009) and Brooks et al. (2011) were used for comparison of EEMT to empirical measures of catchment scale water and energy partitioning (data available at http://www.nws.noaa.gov/oh/mopex). The selected catchments have minimal snow storage to avoid issues of winter-to-spring water carryover or snow water loss to sublimation, and are predominantly located in the southeastern United States, with a few from the western Pacific states of the United States. The selected catchments span a broad climate space with substantial variation in water availability and vegetation cover (Duan et al., 2006).

The MOPEX data used here were derived from the analysis of Brooks et al. (2011) that expanded the data record for the selected catchments to cover 2000 to 2008 water years using daily streamflow data from the US Geological Survey (available at http://waterdata.usgus.gov/nwis/dv/) and monthly climate data from the Parameter-elevation Regressions on Independent Slopes Model (PRISM) (available at http://www.prism.oregonstate.edu/) (Daly et al., 2002). The PRISM data were spatially averaged within each catchment and monthly temperature data used to calculate PET using the Hamon's equation (Hamon, 1961). Daily streamflow values, $Q$, were partitioned to baseflow, $F$, and quick runoff, SR, and summed to provide monthly and annual values for each parameter (see Brooks et al., 2011 for full detail on partitioning methods).

Catchment functioning was quantified using empirical measures of annual water and energy partitioning as quantified by the Budyko curve (Budyko, 1974) and the Horton Index (HI) (Horton, 1933; Troch et al., 2009) using data derived from the MOPEX data. The Budyko curve represents catchment water and energy balance data arrayed in the space defined by actual evapotranspiration over precipitation (AET/PPT) versus potential evapotranspiration over precipitation (PET/PPT) and describes the relative partitioning of precipitation to actual evapotranspiration for a given potential evaporative demand and precipitation space. Catchments where PET/PPT $<1$ represent energy-limited systems where the amount of precipitation exceeds the evaporative demand, whereas values of PET/PPT $>1$ represent waterlimited systems. Actual evapotranspiration was calculated as: $\mathrm{AET}=\mathrm{PPT}-Q$. The Horton Index is a dimensionless number ranging from 0 to 1 that describes the fraction of catchment wetting, $W$, partitioned to evapotranspiration calculated as: $\mathrm{HI}=\mathrm{ET} / W=(\mathrm{PPT}-Q) /(\mathrm{PPT}-\mathrm{SR})$.

Effective energy and mass transfer for each catchment was determined using a combination of the MOPEX data and modeled NPP. Specifically, the $E_{\mathrm{PPT}}$ term was calculated as noted previously: $E_{\mathrm{PPT}}=F \cdot c_{\mathrm{W}} \cdot \Delta T$, where $F$ is mass flux of precipitation to base flow estimated from the MOPEX data. Net primary production and $E_{\mathrm{BIO}}$ were calculated as described above.

\section{Results}

\subsection{Physical constraints on effective energy and mass transfer}

Locations with positive EEMT clustered near the saturated vapor pressure line across all temperatures (Fig. 2a). Statespace limits on EEMT were determined by re-projecting the data in VPD- $T$ space (Fig. 2b). The upper VPD limit for EEMT was defined using two functions with a functional break point of $292 \mathrm{~K}$. Below $292 \mathrm{~K}$, the VPD limit was derived using a modified form of the Clausius-Clapeyron function: $\mathrm{VPD}_{T}=\mathrm{VPD}_{\mathrm{o}} \exp \left[\frac{L_{\mathrm{V}}}{R_{\mathrm{V}}}\left(\frac{1}{T_{\mathrm{o}}}-\frac{1}{T}\right)\right]$, where $\mathrm{VPD}_{\mathrm{o}}$ is a reference vapor pressure deficit of $350 \mathrm{~Pa}$ at $T_{\mathrm{O}}$ of $273.16 \mathrm{~K}$, and $\mathrm{VPD}_{T}$ is equivalent to the upper bound of EEMT production at temperature $T$. The value for $\mathrm{VPD}_{\mathrm{O}}$ was determined through an iterative process constraining $\mathrm{VPD}_{T}$ values to fall 

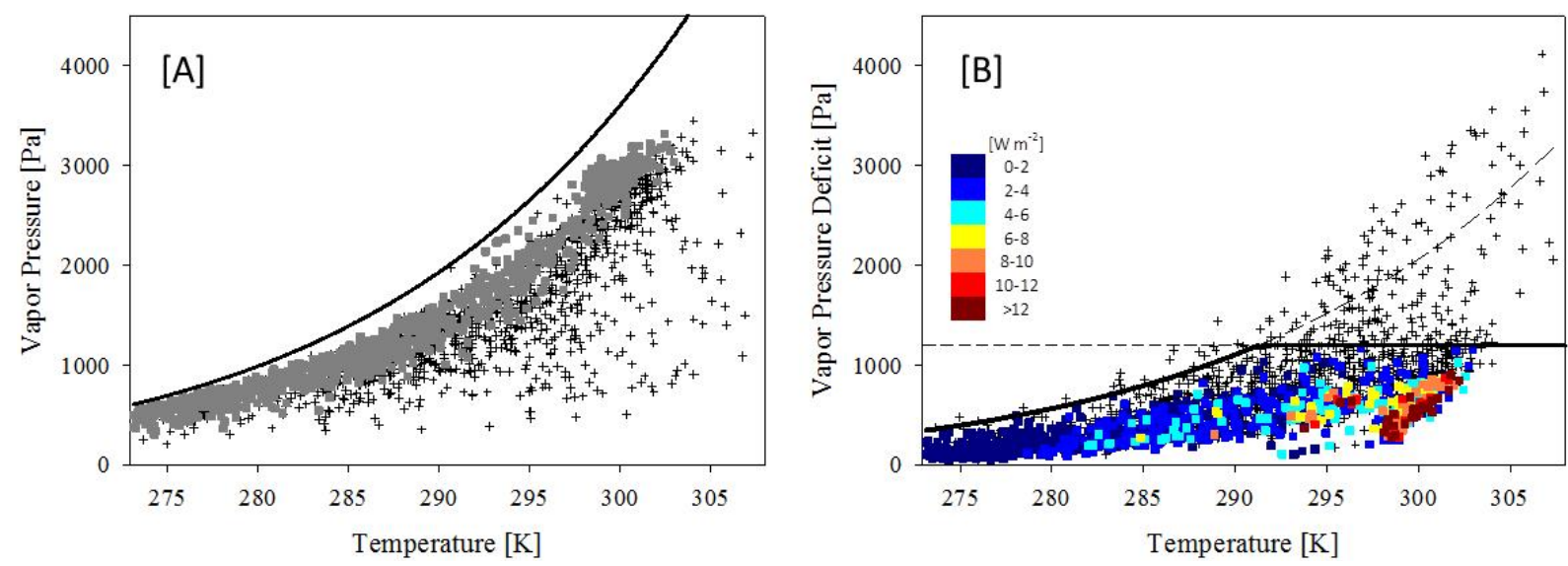

Fig. 2. Climate data in (a) vapor pressure and temperature and (b) vapor pressure deficit and temperature state space. The solid line in (a) is the saturated vapor pressure line, the gray squares are locations of positive effective energy and mass transfer (EEMT), and cross hairs are locations of zero EEMT. In (b), the solid lines indicate the upper physical limit of EEMT as defined using a modified Clausius-Clapeyron equation for locations temperature $<292 \mathrm{~K}$ and set at $1200 \mathrm{~Pa}$ for locations with temperature $>292 \mathrm{~K}$; dashed lines indicate the extension of those limits beyond their point of intersection. The colored squares are locations of positive EEMT scaled with increasing EEMT, and cross hairs are locations of zero EEMT.

above the VPD of locations with positive EEMT for a given temperature. This limit maintains the thermodynamic scaling inherent in the Clausius-Clapeyron equation and captures the non-linear temperature dependent change in the upper VPD bound for locations with temperature $<292 \mathrm{~K}$. At temperatures greater than $292 \mathrm{~K}$, an upper VPD boundary was defined at $1200 \mathrm{~Pa}$ based on visual inspection of the data. The VPD boundaries may be related directly to the thermodynamically defined phase change of liquid water to water vapor in that these limits represent the vapor pressure deficit where the evaporative demand for water supersedes the potential for water partitioning to primary production or base flow at a given temperature.

The locations with monthly VPD greater than $1200 \mathrm{~Pa}$ occurred in the low- to mid-latitudes ranging from $\sim 12$ to $50^{\circ}$ absolute latitude (Fig. 3 and Table 1). Ecosystems that exhibit values above $1200 \mathrm{~Pa}$ were predominantly characterized as tropical and subtropical grassland, savanna, and shrubland, desert scrub, moist tropical and subtropical forest, temperate grassland, savanna, and shrubland, and Mediterranean scrub (Fig. 3 inset) (ecosystem distribution derived from the WWF terrestrial ecoregion dataset available at http://www. worldwildlife.org/science/data/terreco.cfm). The data indicate that all of these systems may experience periods of water limitation thereby limiting production of EEMT (Table 1).

\subsection{PPT-EEMT function}

For a given VPD- $T$ space, the generalized statement of Eq. (3) takes the form of: $\operatorname{dEEMT}=\left(\frac{\partial E E M T}{\partial P P T}\right)_{\mathrm{VPD}, T} \mathrm{dPPT}$. The data indicated that the rate of EEMT generally increased with temperature within the vapor pressure deficit limits defined above (Fig. 2b). Further, the data indicated

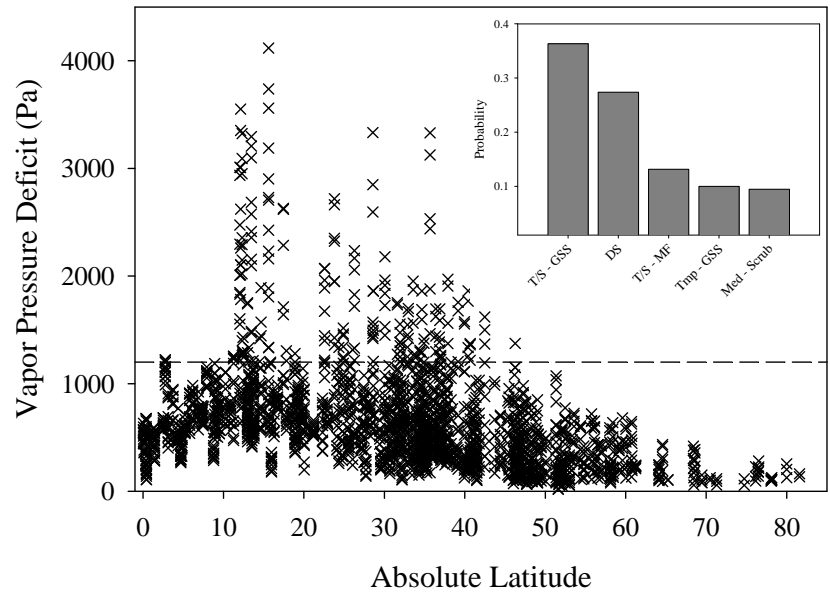

Fig. 3. The global relationship of monthly vapor pressure deficit to absolute latitude for the IAEA dataset. The inset shows the probability distribution function for those ecosystems that experience monthly vapor pressure deficit greater than $1200 \mathrm{~Pa}$. Global ecosystem distribution was taken from the WWF terrestrial ecoregion dataset available at http://www.worldwildlife.org/science/data/ terreco.cfm. The ecosystems include tropical and subtropical grassland, savanna and shrubland (T/S-GSS), desert scrub (DS), tropical and subtropical moist forest (T/S-MF), temperate grassland, savanna and shrubland (Tmp-GSS), and Mediterranean scrub (MedScrub).

that EEMT tended to increase linearly with precipitation at a given temperature.

The data were thus binned at $1{ }^{\circ} \mathrm{K}$ intervals to explicitly define temperature dependent EEMT-PPT functions within the vapor pressure deficit bounds. Examination of the binned data indicated strong and significant linear correlation 


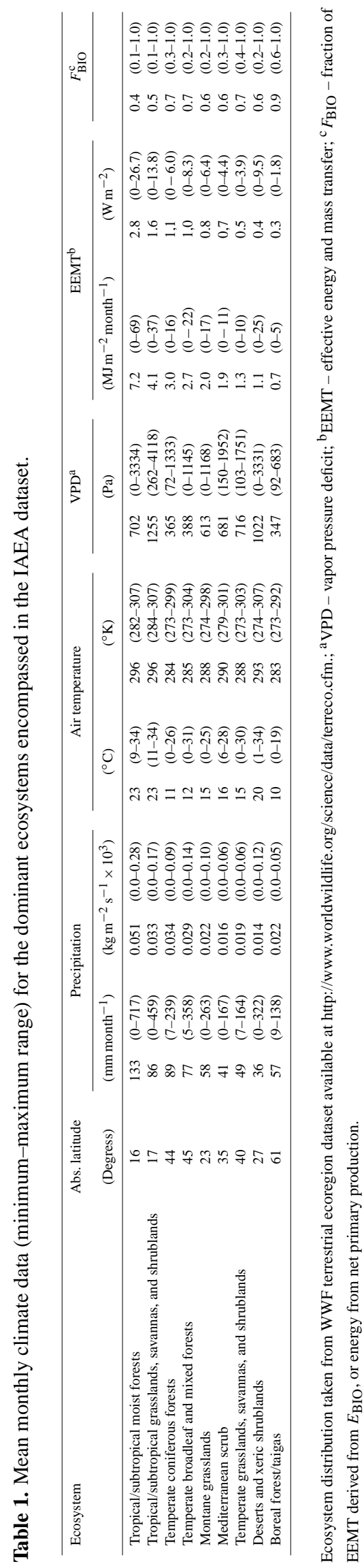


between precipitation and EEMT across all temperature bins in the form:

$\mathrm{EEMT}_{T}=\left(\frac{\mathrm{dEEMT}}{\mathrm{dPPT}}\right)_{T} \mathrm{PPT}+b_{T}, \quad\left[\mathrm{~W} \mathrm{~m}{ }^{-2}\right]$

where $\mathrm{EEMT}_{T}$ is effective energy and mass transfer at a given temperature, $\left(\frac{\mathrm{dEEMT}}{\mathrm{dPPT}}\right)_{T}\left[\mathrm{~J} \mathrm{~kg}^{-1}\right]$ is the slope of the function at a given temperature and represents the potential production of EEMT per unit of precipitation (note that the units of $\left(\frac{\mathrm{dEEMT}}{\mathrm{dPPT}}\right)_{T}$ are $\left[\mathrm{W} \mathrm{m}^{-2}\right] /\left[\mathrm{kg} \mathrm{m}^{-2} \mathrm{~s}^{-1}\right]$, equivalent to $\mathrm{J} \mathrm{kg}^{-1}$ given that $1 \mathrm{~W} \mathrm{~m}^{-2}=\mathrm{J} \mathrm{m}^{-2} \mathrm{~s}^{-1}$ ), and $b_{T}\left[\mathrm{~W} \mathrm{~m}^{-2}\right.$ ] is the intercept for a given temperature. Locations with zero EEMT were excluded from each temperature bin when solving Eq. (6). The temperature dependent EEMT-PPT functions accurately reproduced modeled EEMT based on monthly $E_{\mathrm{PPT}}$ and $E_{\mathrm{BIO}}$ calculations with a root mean square error (RMSE) of $0.36 \mathrm{~W} \mathrm{~m}^{-2}$ around the $1: 1$ line (Fig. 4).

The slope of the individual temperature functions $\left(\frac{\text { dEEMT }}{\text { dPPT }}\right)_{T}$ demonstrated a strong linear relationship to temperature in the form: $\left(\frac{\mathrm{dEEMT}}{\mathrm{dPPT}}\right)_{T}=4.15 T-1136 ; r^{2}=0.98$, $P<0.0001$, and RMSE $=5.45 \mathrm{~J} \mathrm{~kg}^{-1}$ (Fig. 5a). These data indicate a strong trend of increased potential conversion of precipitation to EEMT with increasing temperature, up to values of $120 \mathrm{MJ}$ of EEMT per kg of precipitation at $\sim 300 \mathrm{~K}$. In contrast, the intercept of Eq. (6) exhibited a strong nonlinear relationship to temperature (Fig. 5b). The intercept remained essentially constant at $\sim 0.5 \mathrm{~W} \mathrm{~m}^{-2}$ for temperatures below $292 \mathrm{~K}$ with a strong non-linear decrease to values of less than $-7 \mathrm{~W} \mathrm{~m}^{-2}$ at temperatures greater than $300 \mathrm{~K}$.

The $x$-intercept of Eq. (6) yields the precipitation rate at zero EEMT, equivalent to:

$\mathrm{PPT}_{0}=-\frac{b_{T}}{\left(\frac{\mathrm{dEEMT}}{\mathrm{dPPT}}\right)_{T}}\left[\mathrm{~kg} \mathrm{~m}^{-2} \mathrm{~s}^{-1}\right]$

where $\mathrm{PPT}_{0}$ may be considered a minimum threshold of precipitation required for EEMT production. Values of $\mathrm{PPT}_{0}$ also exhibited a strong non-linear relationship to temperature, with values less than zero at temperatures below $292 \mathrm{~K}$, and positive values, that increased with temperature up to $0.06 \mathrm{~kg} \mathrm{~m}^{-2} \mathrm{~s}^{-1}$ for temperatures ranging from 292 to $305 \mathrm{~K}$ (Fig. 5c). Negative $\mathrm{PPT}_{0}$ values indicate that any precipitation entering the system may be converted to EEMT, whereas positive $\mathrm{PPT}_{0}$ quantifies the minimum amount of precipitation needed for EEMT production. The noted non-linear transition in $b_{T}$ (Fig. 5b) and negative to positive transition in $\mathrm{PPT}_{0}$ (Fig. $5 \mathrm{c}$ ) quantify a threshold in precipitation required to produce EEMT. Further, the break in scaling of $b_{T}$ and $\mathrm{PPT}_{0}$ at $292 \mathrm{~K}$ corresponds with the transition to an upper vapor pressure deficit bound of $1200 \mathrm{~Pa}$. The values of $\mathrm{PPT}_{0}$ scaled directly with the minimum potential evapotranspiration for temperatures greater than 292 K (Fig. 6b). Minimum potential evapotranspiration

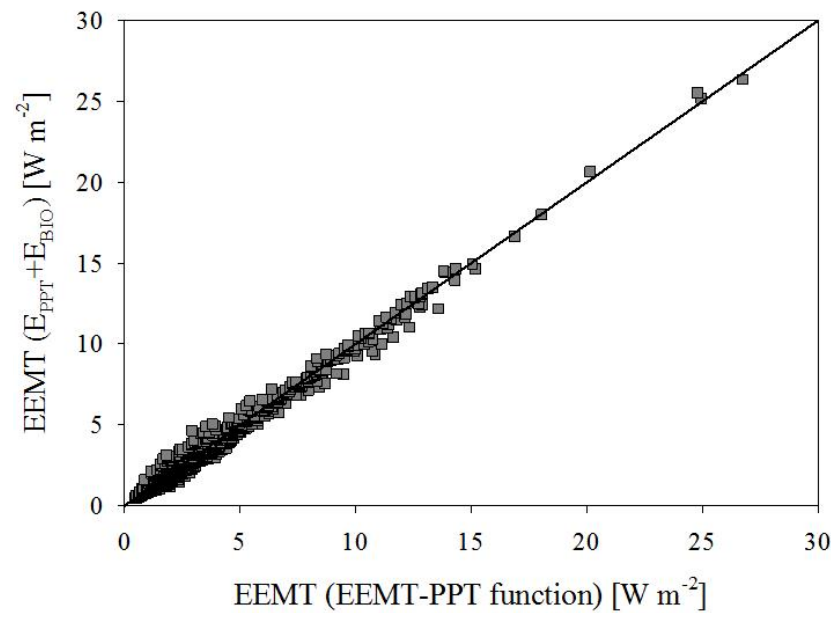

Fig. 4. Relationship of effective energy and mass transfer (EEMT) derived from empirical estimates of energy associated with primary production $\left(E_{\mathrm{BIO}}\right)$ and effective precipitation $\left(E_{\mathrm{PPT}}\right)$ relative to EEMT predicted with temperature dependent EEMT-PPT function. Solid line is the 1:1 line. A close fit between these data is expected, but demonstrates that the EEMT-PPT function effectively describes the $E_{\mathrm{BIO}}+E_{\mathrm{PPT}}$.

estimates $\left(\mathrm{PET}_{\min }\right)$ may be expressed as a function of temperature: $\mathrm{PET}_{\min }=0.31 \mathrm{exp}^{0.999 T}\left[\mathrm{~kg} \mathrm{~m}^{-2} \mathrm{~s}^{-1}\right], r^{2}=0.99$, $P<0.0001$, and RMSE $=0.0026 \mathrm{~kg} \mathrm{~m}^{-2} \mathrm{~s}^{-1}$ (Fig. 6a).

The data thus quantify three physical limits on monthly EEMT: (i) the VPD- $T$ space defined by a modified ClausiusClapeyron function for temperatures $<292 \mathrm{~K}$; (ii) an upper vapor pressure deficit limit of $1200 \mathrm{~Pa}$ for temperatures $>292 \mathrm{~K}$; and (iii) a precipitation threshold that increases with temperature coincident with minimum values for potential evapotranspiration. Within these bounds, EEMT scales linearly with PPT as a function of temperature:

If $T<292 \mathrm{~K}$ and $\mathrm{VPD}>\mathrm{VPD}_{\mathrm{o}} \exp \left[\frac{L_{\mathrm{V}}}{R_{\mathrm{V}}}\left(\frac{1}{T_{\mathrm{o}}}-\frac{1}{T}\right)\right]$ $\mathrm{EEMT}=0$

If $T>292 \mathrm{~K}$ and VPD $>1200 \mathrm{~Pa}$

$\mathrm{EEMT}=0$

If $T>292 \mathrm{~K}$ and PPT $<0.31 \exp ^{0.999 T} \quad$ EEMT $=0$

Else

$$
\mathrm{EEMT}_{T}=\left(\frac{\mathrm{dEEMT}}{\mathrm{dPPT}}\right)_{T} \mathrm{PPT}+b_{T} .
$$

The bounds defined here are strongly temperature dependent. Temperature is a primary parameter in the calculation of both $E_{\mathrm{PPT}}$ and $E_{\mathrm{BIO}}$ through temperature controls on PET, the specific heat of water in the calculation of $E_{\mathrm{PPT}}$, and the temperature dependent modified NPP equation of Leith (1975). Direct empirical measures of EEMT may prove to be not as sensitive to temperature as the results presented here. However, previous work and relations presented below indicate this model formulation correlates well with measures of critical zone function and structure. 

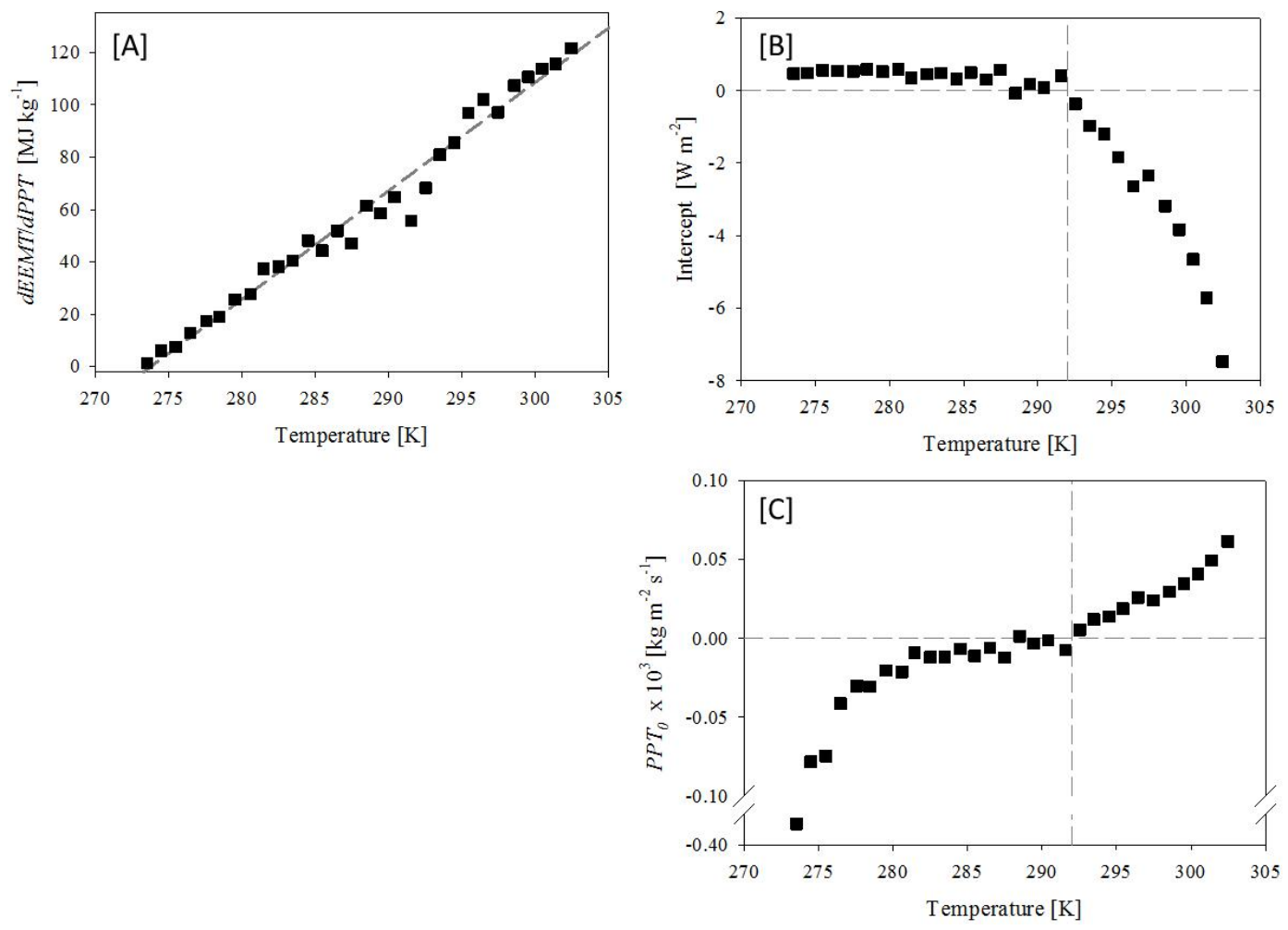

Fig. 5. Linear equation parameters relating effective energy and mass transfer (EEMT) to precipitation for $1^{\circ} \mathrm{K}$ temperature bins relative to temperature: (a) slope, (b) $y$-intercept, (c) intercept/slope equivalent to $x$-intercept. The dashed lines in (b) and (c) note the break point in the functional relationship of the $y$-intercept and $x$-intercept relative to temperature.
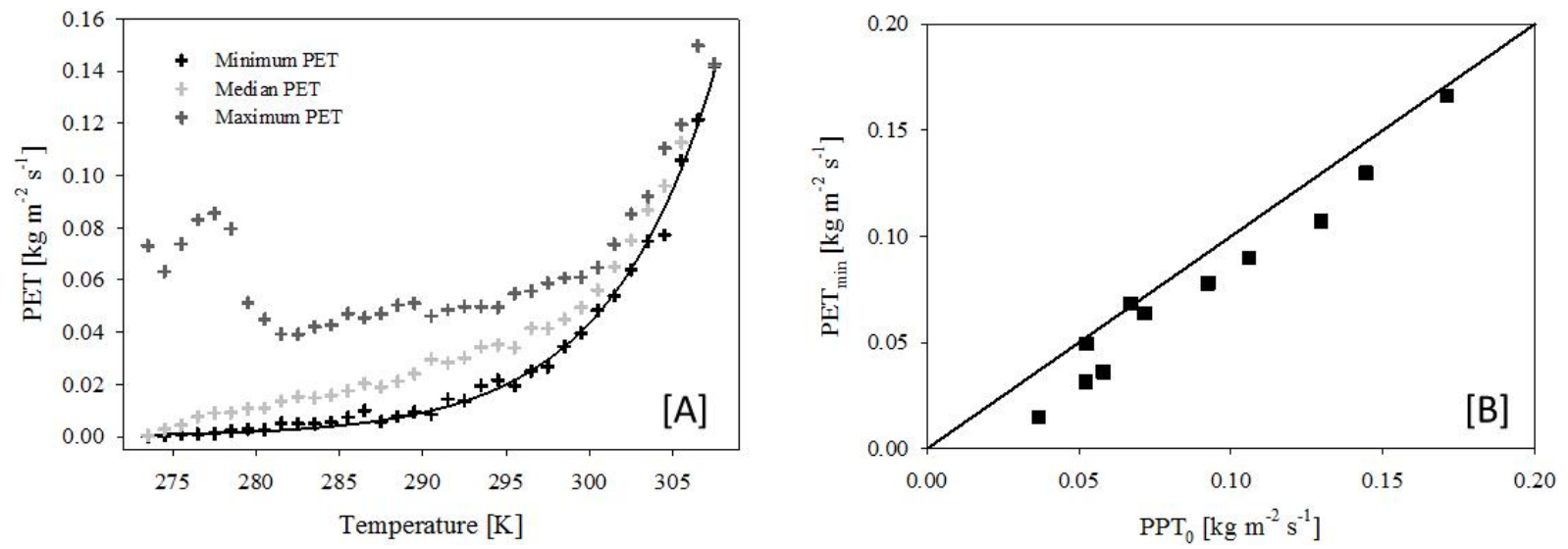

Fig. 6. The (a) maximum, median, and minimum potential evapotranspiration (PET) as determined using Thorthwaite-Mather (1957) relative to temperature, and (b) the mean minimum estimated potential evapotranspiration $\left(\mathrm{PET}_{\mathrm{min}}\right)$ for one degree temperature bins relative to the precipitation threshold $\left(\mathrm{PPT}_{0}\right)$ required for effective energy and mass transfer.

\subsection{Biological and physical partitioning of EEMT}

The fraction of EEMT derived from biological production $\left(F_{\mathrm{BIO}}\right)$ was quantified as: $F_{\mathrm{BIO}}=\frac{E_{\mathrm{BIO}}}{\mathrm{EEMT}}$ [unitless]. Previous work indicated much stronger correlation of EEMT to critical zone properties for systems dominated by $E_{\mathrm{PPT}}$ and a $F_{\mathrm{BIO}}<0.5$, suggesting the relative partitioning of
EEMT to $E_{\mathrm{BIO}}$ and $E_{\mathrm{PPT}}$ is an important parameter for constraining critical zone evolution (Rasmussen et al., 2011b). The $F_{\mathrm{BIO}}$ term decreased exponentially with increasing EEMT (Fig. 7) indicating "low" EEMT systems dominated by $E_{\mathrm{BIO}}$ and "high" EEMT systems dominated by $E_{\mathrm{PPT}}$. The $F_{\mathrm{BIO}}=0.5$ transition occurs in the EEMT region of 
$1-4 \mathrm{~W} \mathrm{~m}^{-2}$ indicating this may be a critical range for determining transitions in critical zone structure and function. Further, for a given EEMT value, $F_{\mathrm{BIO}}$ varied predictably with temperature (Fig. 7). The relationship of $F_{\mathrm{BIO}}$ to EEMT and temperature was characterized for each temperature bin with the function:

$$
\left.F_{\mathrm{BIO}-T}=\left(F_{\mathrm{BIO}-\mathrm{ref}}\right)_{T} \mathrm{EEMT}^{C_{T}} \quad \text { [unitless }\right],
$$

where $F_{\mathrm{BIO}-T}$ is the fraction of EEMT partitioned to $E_{\mathrm{BIO}}$ at a given temperature, $\left(F_{\mathrm{BIO}-\text { ref }}\right)_{T}$ is a reference $F_{\mathrm{BIO}}$, and $c_{T}$ an exponent describing the functional relationship of $F_{\mathrm{BIO}}$ to EEMT. The parameters for Eq. (8) varied with temper-

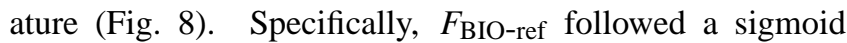
function with increasing temperature reflecting the empirical function used to quantify net primary production ( $\mathrm{Li}-$ eth, 1975), whereas $c_{T}$ was relatively constant at a value of -1.0 across all temperatures except for temperatures less than $275 \mathrm{~K}$ where $c_{T}$ increased to values near -0.7 . This strong temperature dependent result is not surprising given that temperature is the sole parameter for estimating NPP for months of PPT > PET for the NPP model used here. The temperature dependence of $F_{\mathrm{BIO}}$ relative to EEMT may well vary with different models or empirical measures of NPP.

\subsection{MOPEX data analysis}

The MOPEX data indicated clear patterns in $F_{\mathrm{BIO}}$ when arrayed in the Budyko curve space (Fig. 9a). The upper bound on AET/PPT is a value of 1 where all available precipitation is partitioned to evapotranspiration. Values for $F_{\text {BIO }}$ increased to $\sim 1$ coincident with AET/PPT approaching 1 across the water-limited space (PET/PPT $>1$ ), indicating EEMT dominance by $E_{\mathrm{BIO}}$ as water becomes dominantly partitioned to evapotranspiration with little to no water available for base flow and $E_{\mathrm{PPT}}$.

There was also a strong negative correlation between $\mathrm{HI}$ and EEMT (Fig. 9b). Similar to the AET/PPT ratio, HI values approaching 1 indicate the majority of water available for catchment wetting partitioned to evapotranspiration. The negative correlation thus reflects decreased water available for primary production and baseflow, the two components of EEMT. Further, these data also demonstrated that $F_{\mathrm{BIO}}$ increased towards 1 as $\mathrm{HI}$ approaches 1 . Both the Budyko curve and the $\mathrm{HI}$ indicate that water-limited catchments where the water balance is dominated by evapotranspiration correspond to low EEMT locations with EEMT dominated by primary production.

\section{Discussion}

The data demonstrated three physical limits for effective energy and mass transfer characterized by vapor pressure deficit, temperature, and precipitation. The limits include: (i) an absolute vapor pressure deficit threshold of $1200 \mathrm{~Pa}$

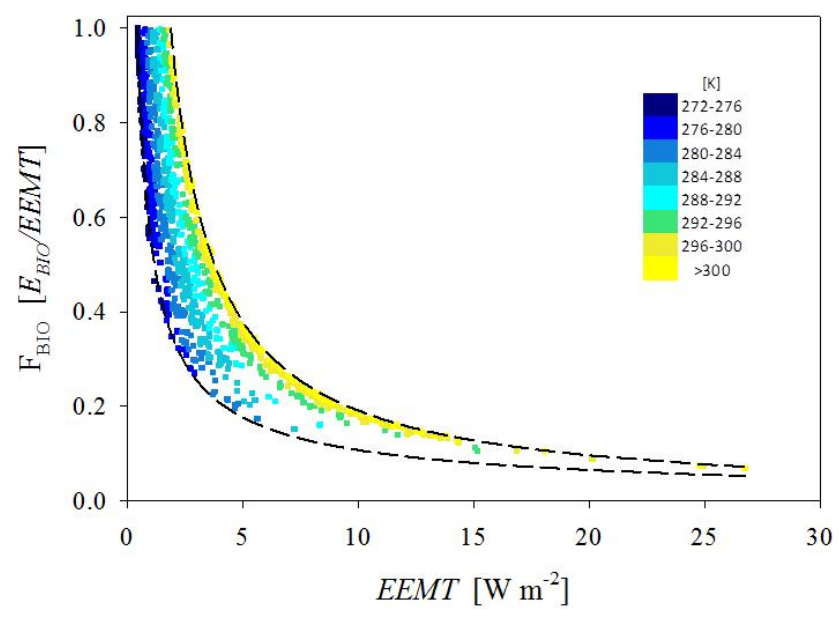

Fig. 7. The fraction $\left(F_{\mathrm{BIO}}\right)$ of effective energy and mass transfer (EEMT) derived from primary production $\left(E_{\mathrm{BIO}}\right)$ relative to EEMT. Upper and lower bounds were calculated as function of temperature: $F_{\mathrm{BIO}-T}=\left(F_{\mathrm{BIO}-\text { ref }}\right)_{T} \mathrm{EEMT}^{C_{T}}$, where $F_{\mathrm{BI} 0 \text {-ref }}$ and $c$ vary as a function of temperature $(T)$. The color scale corresponds to temperature.

above which EEMT is zero; (ii) a temperature dependent vapor pressure deficit limit that scales with temperature following the slope of the saturated vapor pressure function up to a temperature of $292 \mathrm{~K}$; and (iii) a precipitation threshold that scales directly to minimum potential evapotranspiration for temperatures greater than $292 \mathrm{~K}$. Within these limits, EEMT scales directly with mass flux of precipitation, with increasing conversion of precipitation to EEMT with increasing temperature. These relationships thus define the state space and physical limits of EEMT. As noted, effective energy and mass transfer has been directly related to critical zone structure and function (Pelletier and Rasmussen, 2009; Rasmussen et al., 2005, 2011b; Rasmussen and Tabor, 2007; Sheldon and Tabor, 2009), such that the limits defined here may also define the climatic state space important for constraining critical zone evolution.

The physical limits for production of EEMT defined here correspond directly to well defined temperature and vapor pressure deficit limits on transpiration, photosynthesis, and primary production; processes mediated by a combination of biophysical controls on plant stomatal conductance and carbon assimilation, and physical controls on evaporation (Law et al., 2002; Aphalo and Jarvis, 1991; Damour et al., 2010; Oren et al., 1999; Jolly et al., 2005; Schulze et al., 1994; Jarvis and McNaughton, 1986; Pieruschka et al., 2010). While EEMT does not include the mass and energy transfer associated with evapotranspiration, the production of EEMT is closely coupled with water, energy and carbon balances as mediated by photosynthesis and evapotranspiration and thus expresses similar physical limits. The physical limits on EEMT suggest two state-space zones of EEMT production that separate at $292 \mathrm{~K}$. The commonality among both 

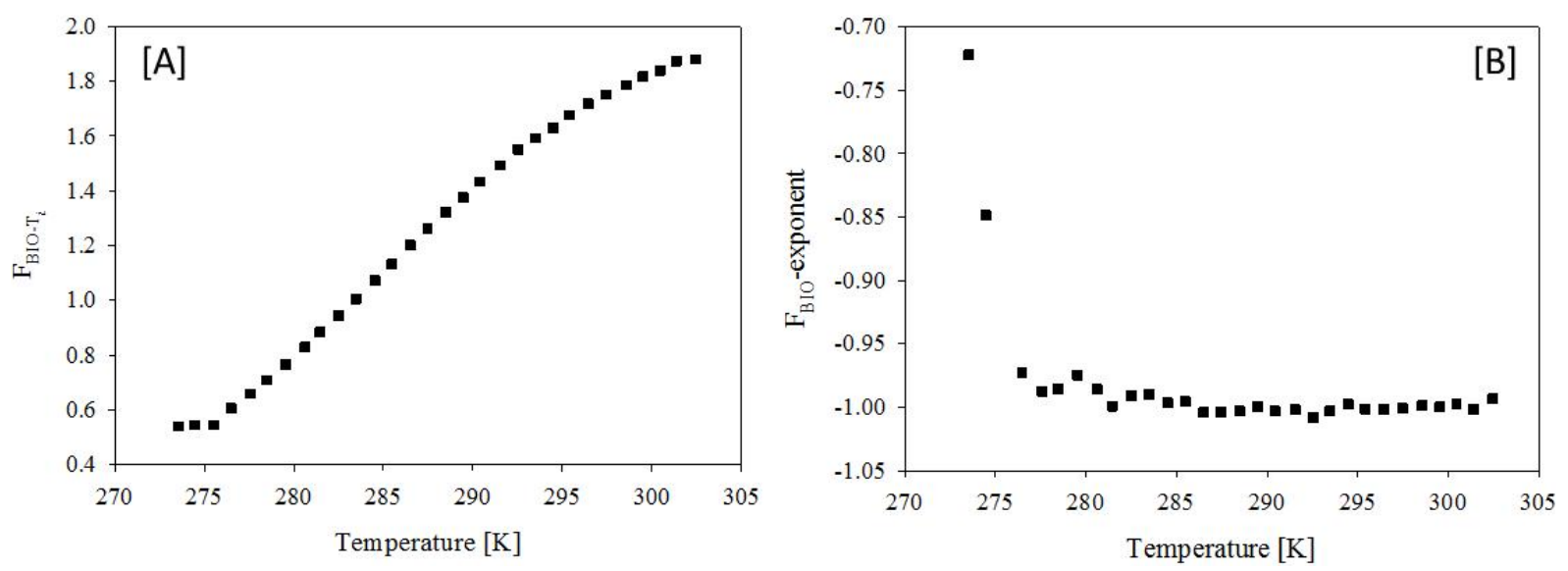

Fig. 8. Temperature dependent equation parameters for the exponential function relating the fraction of effective energy and mass transfer $\left(\right.$ EEMT) derived from primary production $\left(F_{\mathrm{BIO}}\right)$ to EEMT in the from: $F_{\mathrm{BIO}-T}=\left(F_{\mathrm{BIO}-\mathrm{ref}}\right)_{T} \mathrm{EEMT} C_{T}$. Both the reference $F_{\mathrm{BIO}}(\mathbf{a})$ and the exponent (b) vary as a function of temperature.
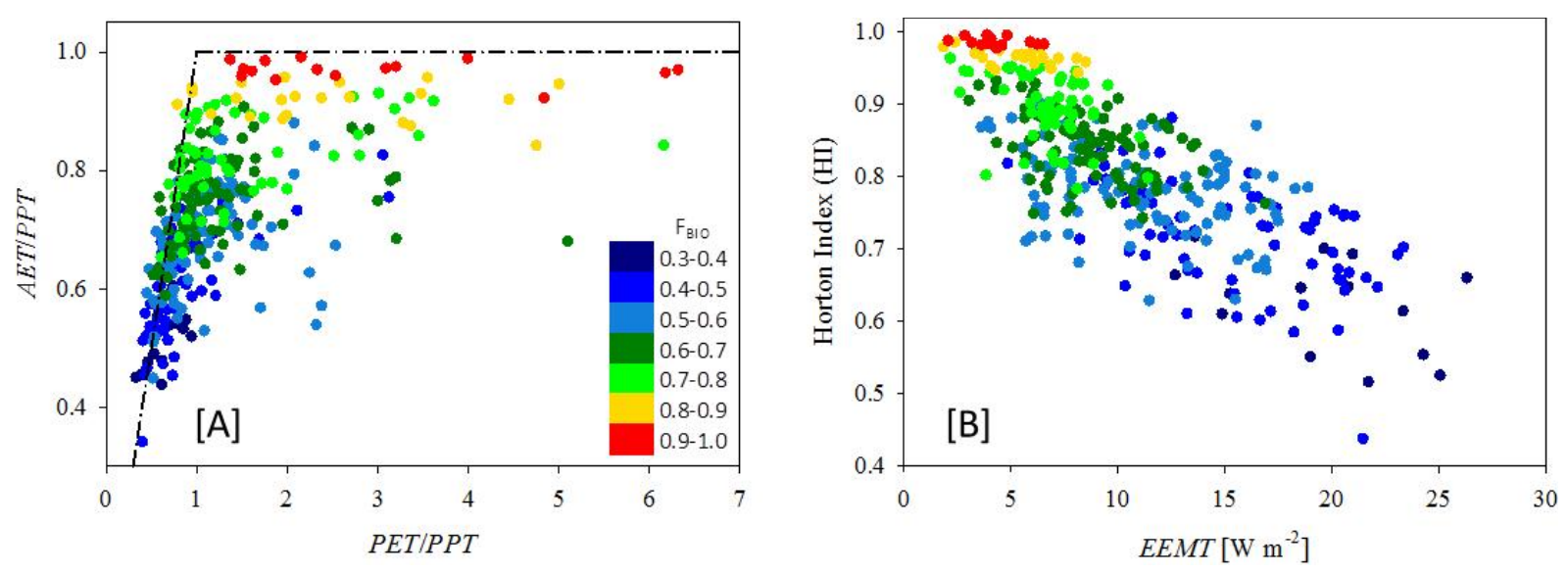

Fig. 9. The (a) Budyko curve plotted as the ratios of actual evapotranspiration (AET) to precipitation (PPT) versus potential evapotranspiration (PET) to precipitation and (b) the Horton Index (HI) relative to effective energy and mass transfer (EEMT) for eighty six MOPEX catchments. The color scale in (a) and (b) correspond to $F_{\mathrm{BIO}}$, defined as the relative fraction of EEMT derived from primary production.

zones is an upper vapor pressure deficit limit above which EEMT goes to zero. These upper limits represent cold/dry and hot/dry conditions, respectively, and indicate strong control of evaporative gradients on EEMT (Table 1).

At temperatures less than $292 \mathrm{~K}$, the upper vapor pressure deficit limit was temperature dependent. The temperature control likely reflects both temperature and solar radiation limitation on EEMT. The enzymes that catalyze photosynthesis are all very temperature dependent such that primary production is limited in cool environments (Berry and Bjorkman, 1980; Holaday et al., 1992). Empirical measures indicate strong decline in stomatal conductance and rates of carbon assimilation with decreases in temperature below $\sim 290 \mathrm{~K}$ across range of species (Stewart, 1988; White et al., 1999; Guardiola-Claramonte et al., 2010; Jarvis, 1976). In terms of radiation limitation, carbon assimilation $\left(A_{\mathrm{c}}\right)$ may be expressed directly as a function of radiation (Monteith,
1977): $A_{\mathrm{c}}=\varepsilon f_{\mathrm{s}} s$ PAR, were $\varepsilon$ is efficiency of conversion of radiation to $A_{\mathrm{c}}, f_{\mathrm{s}}$ is the fraction of intercepted radiation, and PAR is photosynthetically active radiation. Carbon assimilation, and thus the $E_{\mathrm{BIO}}$ term of EEMT, is limited in the high latitude systems by available photosynthetic radiation and by temperature in the high elevation systems. Therefore, despite the relatively low vapor pressure deficits at these locations that would favor maximum stomatal conductance, carbon assimilation and primary production are limited by a combination of low temperatures and/or available photosynthetic radiation. Further, given that $E_{\mathrm{PPT}}$ is a function of both water in excess of evapotranspiration and temperature, the transfer of $E_{P P T}$ is directly limited by low temperatures, even in locations with substantial water in excess of evapotranspiration. As a result, the potential EEMT produced per unit precipitation was minimal in these systems, less than $40 \mathrm{MJ} \mathrm{kg}^{-1}$, and tends to be dominated by $E_{\mathrm{BIO}}$. Thus these 
systems have the potential for limited primary production and flushing of cold water through the subsurface, indicating limited potential for chemical weathering and subsurface structural development due to temperature limitations and kinetic constraint on weathering reactions (Kump et al., 2000). This is reflected in local- (Rasmussen and Tabor, 2007) to global-scale (Rasmussen et al., 2011b) synthesis of soil properties relative to EEMT in that relatively cold, low EEMT systems exhibit minimal soil development and limited chemical weathering. Note that the EEMT formulation presented here does not account for freeze-thaw work and rock shattering in cold environments that can form relatively deep regolith profiles (Ollier and Pain, 1996).

For warm systems ( $T>292 \mathrm{~K}$ ), the upper vapor pressure deficit limit of $1200 \mathrm{~Pa}$ corresponds with empirical and modeled data indicating substantial reduction in stomatal conductance and leaf to canopy level transpiration at vapor pressure deficits greater than $1200 \mathrm{~Pa}$ (Damour et al., 2010; Pieruschka et al., 2010; Oren et al., 1999). Carbon assimilation via photosynthesis is directly related to stomatal conductance such that decreased stomatal conductance at high vapor pressure deficit equates to a reduction in carbon assimilation and primary production (Schulze et al., 1994). Further, the relative partitioning of water to transpiration and assimilation is strongly controlled by vapor pressure deficit, with increased water loss to transpiration with increasing vapor pressure deficit. For these systems, carbon assimilation may be expressed as a function of transpiration and vapor pressure deficit (Campbell and Norman, 2000): $A_{\mathrm{c}}=k E / \mathrm{VPD}$ where $E$ is transpiration, and $k$ is equivalent to the ratio of stomatal and atmospheric vapor conductance, and the gradient between atmospheric and interleaf $\mathrm{CO}_{2}$ concentrations, $\frac{g_{\mathrm{c}}}{g_{\mathrm{v}}}\left(C_{a}-C_{i}\right)$ (Farquhar et al., 1980). Given a constant value for $k$, the rate of carbon assimilation per unit transpiration decreases as vapor pressure deficit increases, resulting in a greater amount of water partitioned to transpirative loss rather than primary production. This corresponds with decreased potential for $E_{\mathrm{BIO}}$ or $E_{\mathrm{PPT}}$ production as systems approach the $1200 \mathrm{~Pa}$ vapor pressure deficit limit in that primary production is reduced, and less effective precipitation is available to flux into the subsurface due to enhanced partitioning of water to transpiration. At vapor pressure deficits greater than $1200 \mathrm{~Pa}$ stomata move towards complete closure, effectively shutting down both transpiration and assimilation. Coincident with these biophysical controls, the physical evaporative demand increases directly with vapor pressure deficit (Kucera, 1954), such that at high vapor pressure deficits precipitation is dominantly partitioned to evaporation. Therefore, the combination of reduced carbon assimilation per unit transpiration and increased physical evaporation strongly favor partitioning of precipitation to evapotranspiration rather than primary production and base-flow, the primary components of EEMT.

The warm systems are thus strongly water-limited with high physical and biophysical demands on available water.
However, if water is available in sufficient amounts and vapor pressure deficit is below $1200 \mathrm{~Pa}$, these systems exhibit the greatest potential for conversion of precipitation to EEMT. Of note, systems with temperatures greater than $292 \mathrm{~K}$ also corresponded with the onset of a threshold precipitation level for EEMT (Fig. 5). The precipitation threshold values scaled directly with the minimum estimates for potential evapotranspiration indicating a minimum amount of precipitation required to overcome a priori evaporative gradients for EEMT production. However, for a given mass flux of precipitation beyond the precipitation threshold, these systems hold the greatest potential for conversion of precipitation to effective energy and mass transfer, with conversion values up to $120 \mathrm{MJ} \mathrm{kg}^{-1}$ of precipitation for systems greater than 300 $\mathrm{K}$. The warm temperatures favor the activity of photosynthetic enzymes and imply sufficient available radiation to drive photosynthesis, factors that favor primary production and $E_{\mathrm{BIO}}$. Further, water in excess of the evapotranspirative in these systems has the potential for carrying substantial heat energy, $E_{\mathrm{PPT}}$, that would favor rapid rates of chemical processes and chemical weathering in the subsurface (White and Brantley, 1995). Indeed, the studies of Rasmussen et al. $(2005,2007,2011 b)$ indicate that soils in warm, high EEMT systems are highly weathered and express substantial subsurface structural development in terms of soil depth, chemical depletion and presence of clay rich subsurface horizons.

These general patterns were confirmed with the MOPEX catchment data that indicated strong negative correlation of EEMT to the relative amount of catchment wetting partitioned to evapotranspiration and that $F_{\mathrm{BIO}}$ values approached 1 with increased water limitation. The relative composition of EEMT ( $E_{\mathrm{BIO}}$ vs. $E_{\mathrm{PPT}}$ ) reflects hydrologic partitioning as illustrated by the Budyko curve. In terms of EEMT, greater $F_{\mathrm{BIO}}$ in the water-limited, low EEMT catchments suggests the energy available to perform work in the subsurface is carbon cycle dominated with limited leaching and removal of solutes or subsurface development and thus favoring shallow soils with minimal chemical denudation or mineral weathering. In contrast, in the energy-limited, high EEMT locations dominated by $E_{\mathrm{PPT}}$ the majority of available work energy comes in the form of baseflow that can participate in chemical weathering reactions, transport solutes and solid matter, and thus produce deep soils with substantial chemical denudation and mineral transformation. Furthermore, Brooks et al. (2011) found negative correlation of vegetative cover to the Horton Index for the same set of catchments, indicating decreased vegetative cover with increased partitioning of catchment wetting to evapotranspiration. Thus, even though a number of factors beyond water use efficiency affect the Horton Index, the data here suggest a positive feedback amongst EEMT and catchment function and evolution, e.g., in the high EEMT catchments, deep soils with greater vegetation cover promote less efficient water use as expressed in the Horton index, such that more baseflow 
is flushed through the critical zone, sustaining subsurface critical zone development. Clearly, soils and vegetation coevolve with climate, leaving distinct patterns that affect landscape hydrology (Berry et al., 2005).

\section{Summary}

The thermodynamic based state-space approach defined here provides a simplified framework with well-defined physical limits for calculating EEMT directly from the mass flux precipitation and the state variables of temperature and vapor pressure deficit. Comparison of EEMT to measures of catchment function demonstrated strong correlation between the magnitude and partitioning of EEMT to biological and physical components and catchment energy and water balance. The simplified approach to constraining EEMT presented here provides a means for directly scaling effective energy and mass transfer from regional to pedon spatial scales. At regional to watershed scales, EEMT estimates as constrained with broad scale climatic state-space variables may be coupled with catchment scale data on discharge, evapotranspiration, base-flow and remotely sensed primary production products (e.g., Troch et al., 2009) to explicitly quantify EEMT in the context of precipitation, temperature and vapor pressure deficit. At hillslope to pedon scales, regional scale temperature and vapor pressure deficit may be downscaled according to local topography and topographic control on solar radiation (Bohner and Antonic, 2009), whereas precipitation may be modified using locally scaled water subsidies based on topographic controlled water routing and redistribution (Thompson et al., 2011) to provide high spatial resolution characterization of effective energy and mass transfer. The state-space framework derived here thus presents the potential for directly integrating regional to pedon scale heterogeneity in effective energy and mass transfer and critical zone structure and function within a common thermodynamic framework.

Acknowledgements. This works was supported NSF grant EAR0724958. I also thank Peter A. Troch, Jonathan D. Phillips and an anonymous reviewer for insightful comments that improved this manuscript.

Edited by: C. de Michele

\section{References}

Amundson, R., Richter, D. D., Humphreys, G. S., Jobbagy, E. G., and Gaillardet, J.: Coupling between biota and earth materials in the Critical Zone, Elements, 3, 327-332, 2007.

Anderson, G. M.: Thermodynamics of natural systems, 2nd Edn., Cambridge University Press, Cambridge, UK, 2005.

Aphalo, P. J. and Jarvis, P. G.: Do Stomata Respond to RelativeHumidity, Plant Cell Environ., 14, 127-132, 1991.
Bejan, A.: Advanced engineering thermodynamics, 3rd Edn., John Wiley \& Sons, Hoboken, N.J., 2006.

Berry, J. and Bjorkman, O.: Photosynthetic Response and Adaptation to Temperature in Higher-Plants, Ann. Rev. Plant. Phys., 31, 491-543, 1980.

Berry, S. L., Farquhar, G. D., and Roderick, M. L.: Co-evolution of climate, vegetation, soil and air, in: Encyclopedia of Hydrological Sciences, edited by: Bloschl, G. and Sivapalan, M., John Wiley and Sons, Ltd., Chichester, UK, 177-192, 2005.

Black, P. E.: Revisiting the Thornthwaite and Mather Water Balance1, J. Am. Water Resour. Assoc., 43, 1604-1605, 2007.

Bohner, J. and Antonic, O.: Land-Surface Parameters Specific to Topo-Climatology, in: Geomorphometry Concepts, Software, Applications, edited by: Hengl, T. and Reuter, H. I., Developments in Soil Science, 33, Elsevier, Amsterdam, 227-254, 2009.

Brantley, S. L., Megonigal, J. P., Scatena, F. N., Balogh-Brunstad, Z., Barnes, R. T., Bruns, M. A., Van Cappellen, P., Dontsova, K., Hartnett, H. E., Hartshorn, A. S., Heimsath, A., Herndon, E., Jin, L., Keller, C. K., Leake, J. R., McDowell, W. H., Meinzer, F. C., Mozdzer, T. J., Petsch, S., Pett-Ridge, J., Pregitzer, K. S., Raymond, P. A., Riebe, C. S., Shumaker, K., Sutton-Grier, A., Walter, R., and Yoo, K.: Twelve testable hypotheses on the geobiology of weathering, Geobiology, 9, 140-165, doi:10.1111/j.14724669.2010.00264.x, 2011.

Brooks, P. D., Troch, P. A., Durcik, M., Gallo, E., and Schlegel, M.: Quantifying regional-scale ecosystem response to changes in precipitation: Not all rain is created equal, Water Resour. Res., 47, W00J08, doi:10.1029/2010WR009762, 2011.

Budyko, M. I.: Climate and Life, Academic, San Diego, CA, 508 pp., 1974.

Campbell, G. S. and Norman, J. M.: An introduction to environmental biophysics, 2nd Edn., Springer, New York, 2000.

Comstock, J. P. and Ehleringer, J. R.: Correlating Genetic-Variation in Carbon Isotopic Composition with Complex Climatic Gradients, P. Natl. Acad. Sci. USA, 89, 7747-7751, 1992.

Daly, C., Gibson, W. P., Taylor, G. H., Johnson, G. L., and Pasteris, P.: A knowledge-based approach to the statistical mapping of climate, Clim. Res., 22, 99-113, 2002.

Damour, G., Simonneau, T., Cochard, H., and Urban, L.: An overview of models of stomatal conductance at the leaf level, Plant Cell Environ., 33, 1419-1438, doi:10.1111/j.13653040.2010.02181.x, 2010.

Duan, Q., Schaake, J., Andreassian, V., Franks, S., Goteti, G., Gupta, H. V., Gusev, Y. M., Habets, F., Hall, A., Hay, L., Hogue, T., Huang, M., Leavesley, G., Liang, X., Nasonova, O. N., Noilhan, J., Oudin, L., Sorooshian, S., Wagener, T., and Wood, E. F.: Model Parameter Estimation Experiment (MOPEX): An overview of science strategy and major results from the second and third workshops, J. Hydrol., 320, 3-17, doi:10.1016/j.jhydrol.2005.07.031, 2006.

Farquhar, G. D., Caemmerer, S. V., and Berry, J. A.: A Biochemical-Model of Photosynthetic $\mathrm{CO}_{2}$ Assimilation in Leaves of C-3 Species, Planta, 149, 78-90, 1980.

Farrar, J. F.: The Respiratory Source of $\mathrm{CO}_{2}$, Plant Cell Environ., 8, 427-438, 1985.

Guardiola-Claramonte, M., Troch, P. A., Ziegler, A. D., Giambelluca, T. W., Durcik, M., Vogler, J. B., and Nullet, M. A.: Hydrologic effects of the expansion of rubber (Hevea brasiliensis) in a tropical catchment, Ecohydrology, 3, 306-314, 
doi:10.1002/Eco.110, 2010.

Hamon, W. R.: Estimating potential evapotranspiration, Proc. Am. Soc. Civil Eng., 87, 107-120, 1961.

Holaday, A. S., Martindale, W., Alred, R., Brooks, A. L., and Leegood, R. C.: Changes in Activities of Enzymes of Carbon Metabolism in Leaves during Exposure of Plants to LowTemperature, Plant Physiol., 98, 1105-1114, 1992.

Horton, R. E.: The role of infiltration in the hydrologic cycle, Trans. Am. Geophys. Union, 14, 446-460, 1933.

Hugget, R. J.: Geoecology, An Evolutionary Approach, Routledge, London, 1995.

Iribarne, J. V. and Godson, W. L.: Atmospheric Thermodynamics, in: Geophysics and Astrophysics Monographs, 2nd Edn., edited by: McCormac, B. M., Kluwer Academic Publishers, Boston, 259 pp., 1981.

Jarvis, P. G.: Interpretation of Variations in Leaf Water Potential and Stomatal Conductance Found in Canopies in Field, Philos. T. Roy. Soc. B, 273, 593-610, 1976.

Jarvis, P. G. and McNaughton, K. G.: Stomatal Control of Transpiration - Scaling up from Leaf to Region, Adv. Ecol. Res., 15, $1-49,1986$.

Jenny, H.: Factors of soil formation; a system of quantitative pedology, 1st Edn., McGraw-Hill book company, Inc., New York, London,, xii, 281 pp., 1941.

Jolly, W. M., Nemani, R., and Running, S. W.: A generalized, bioclimatic index to predict foliar phenology in response to climate, Global Change Biol., 11, 619-632, doi:10.1111/j.13652486.2005.00930.x, 2005.

Jørgensen, S. E. and Fath, B. D.: Application of thermodynamic principles in ecology, Ecol. Complex., 1, 267-280, 2004.

Kleidon, A.: Nonequilibrium thermodynamics and maximum entropy production in the Earth system, Naturwissenschaften, 96, 653-677, 2009.

Kleidon, A.: Non-equilibrium thermodynamics, maximum entropy production and Earth-system evolution, Philos. T. R. Soc. A, 368, 181-196, doi:10.1098/rsta.2009.0188, 2010.

Kucera, C. L.: Some Relationships of Evaporation Rate to Vapor Pressure Deficit and Low Wind Velocity, Ecology, 35, 71-75, 1954.

Kump, L. R., Brantley, S. L., and Arthur, M. A.: Chemical Weathering, Atmospheric $\mathrm{CO}_{2}$, and Climate, Ann. Rev. Earth Planet. Sci., 28, 611-667, doi:10.1146/annurev.earth.28.1.611, 2000.

L'vovich, M. I.: World water resources and their future, Original in Russian, English translation American Geophysical Union, Washington, D.C., 1979.

Law, B. E., Falge, E., Gu, L., Baldocchi, D. D., Bakwin, P., Berbigier, P., Davis, K., Dolman, A. J., Falk, M., Fuentes, J. D., Goldstein, A., Granier, A., Grelle, A., Hollinger, D., Janssens, I. A., Jarvis, P., Jensen, N. O., Katul, G., Mahli, Y., Matteucci, G., Meyers, T., Monson, R., Munger, W., Oechel, W., Olson, R., Pilegaard, K., Paw, K. T., Thorgeirsson, H., Valentini, R., Verma, S., Vesala, T., Wilson, K., and Wofsy, S.: Environmental controls over carbon dioxide and water vapor exchange of terrestrial vegetation, Agr. Forest Meteorol., 113, 97-120, doi:S01681923(02)00104-1, 2002.

Lieth, H.: Primary production of the major vegetation units of the world, in: Primary Productivity of the Biosphere, edited by: Leith, H. and Whittaker, R. H., Springer-Verlag, New York, NY, 203-215, 1975.
Lin, H.: Linking principles of soil formation and flow regimes, J. Hydrol., 393, 3-19, doi:10.1016/j.jhydrol.2010.02.013, 2010.

Lovett, G., Cole, J., and Pace, M.: Is net ecosystem production equal to ecosystem carbon accumulation?, Ecosystems, 9, 152$155,2006$.

Melillo, J., McGuire, A. D., Kicklighter, D., Moore, B., Vorosmarty, C. J., and Schloss, A. L.: Global climate change and terrestrial net primary productivity, Nature, 363, 234-240, 1993.

Minasny, B., McBratney, A. B., and Salvador-Blanes, S.: Quantitative models for pedogenesis - A review, Geoderma, 144, 140 157, 2008.

Monteith, J. L.: Evaporation and environment, in: Symposium of the Society for Experimental Biology, The State and Movement of Water in Living Organisms, edited by: Fogg, G. E., Academic Press, Inc., New York, 205-234, 1965.

Monteith, J. L.: Climate and Efficiency of Crop Production in Britain, Philos. T. Roy. Soc. B, 281, 277-294, 1977.

NRC: Basic Research Opportunities in Earth Sciences, National Research Council, Washington, D.C., 2001.

NRC: Landscapes on the Edge: New Horizons for Research on Earth's Surface, The National Academies Press, New York, NY, 163 pp., 2010.

Odum, H. T.: Self-Organization, Transformity, and Information, Science, 242, 1132-1139, 1988.

Ollier, C. and Pain, C. F.: Regolith, soils and landforms, John Wiley, Chichester, New York, 1996.

Oren, R., Sperry, J. S., Katul, G. G., Pataki, D. E., Ewers, B. E., Phillips, N., and Schafer, K. V. R.: Survey and synthesis of intraand interspecific variation in stomatal sensitivity to vapour pressure deficit, Plant Cell Environ., 22, 1515-1526, 1999.

Ozawa, H., Ohmura, A., Lorenz, R. D., and Pujol, T.: The second law of thermodynamics and the global climate system: A review of the maximum entropy production principle, Rev. Geophys., 41, 1018, doi:10.1029/2002rg000113, 2003.

Pelletier, J. D. and Rasmussen, C.: Quantifying the climatic and tectonic controls on hillslope steepness and erosion rate, Lithosphere, 1, 73-80, 2009.

Penman, H. L.: Natural Evaporation from Open Water, Bare Soil and Grass, P. Roy. Soc. Lond. A, 193, 120-145, 1948.

Phillips, J. D.: On the relations between complex systems and the factorial model of soil formation (with Discussion), Geoderma, 86, 1-21, 1998.

Phillips, J. D.: Biological Energy in Landscape Evolution, Am. J. Sci., 309, 271-289, 2009.

Pieruschka, R., Huber, G., and Berry, J. A.: Control of transpiration by radiation, P. Natl. Acad. Sci. USA, 107, 13372-13377, doi:10.1073/pnas.0913177107, 2010.

Pope, G. A., Dorn, R. I., and Dixon, J. C.: A new conceptual model for understanding geographical variations in weathering, Ann. Assoc. Am. Geogr., 85, 38-64, 1995.

Rasmussen, C. and Tabor, N. J.: Applying a quantitative pedogenic energy model across a range of environmental gradients, Soil Sci. Soc. Am. J., 71, 1719-1729, 2007.

Rasmussen, C., Southard, R. J., and Horwath, W. R.: Modeling energy inputs to predict pedogenic environments using regional environmental databases, Soil Sci. Soc. Am. J., 69, 1266-1274, 2005. 
Rasmussen, C., Brantley, S., Richter, D. D., Blum, A., Dixon, J., and White, A. F.: Strong climate and tectonic control on plagioclase weathering in granitic terrain, Earth Planet. Sc. Lett., 301, 521-530, doi:10.1016/j.epsl.2010.11.037, 2011a.

Rasmussen, C., Troch, P. A., Chorover, J., Brooks, P., Pelletier, J., and Huxman, T. E.: An open system framework for integrating critical zone structure and function, Biogeochemistry, 102, 1529, doi:10.1007/s10533-010-9476-8, $2011 \mathrm{~b}$.

Rinaldo, A., Rodriguez-Iturbe, I., and Rigon, R.: Channel networks, Ann. Rev. Earth Planet. Sci., 26, 289-327, 1998.

Running, S. W. and Coughlan, J. C.: A General-Model of Forest Ecosystem Processes for Regional Applications, 1. Hydrologic Balance, Canopy Gas-Exchange and Primary Production Processes, Ecol. Modell., 42, 125-154, 1988.

Schimel, D. S., Emanuel, W., Rizzo, B., Smith, T., Woodward, F. I., Fisher, H., Kittel, T. G. F., McKeown, R., Painter, T., Rosenbloom, N., Ojima, D. S., Parton, W. J., Kicklighter, D. W., McGuire, A. D., Melillo, J. M., Pan, Y., Haxeltine, A., Prentice, C., Sitch, S., Hibbard, K., Nemani, R., Pierce, L., Running, S., Borchers, J., Chaney, J., Neilson, R., and Braswell, B. H.: Continental scale variability in ecosystem processes: Models, data, and the role of disturbance, Ecol. Monogr., 67, 251-271, 1997.

Schneider, E. D. and Kay, J. J.: Life as a Manifestation of the 2nd Law of Thermodynamics, Math. Comput. Modell., 19, 2548, 1994.

Schulze, E. D., Kelliher, F. M., Korner, C., Lloyd, J., and Leuning, R.: Relationships among Maximum Stomatal Conductance, Ecosystem Surface Conductance, Carbon Assimilation Rate, and Plant Nitrogen Nutrition - a Global Ecology Scaling Exercise, Ann. Rev. Ecol. Systemat., 25, 629-660, 1994.

Sheldon, N. D. and Tabor, N. J.: Quantitative paleoenvironmental and paleoclimatic reconstruction using paleosols, Earth-Sci. Rev., 95, 1-52, 2009.

Sivapalan, M.: Pattern, process and function: Elements of a unified theory of hydrology at the catchment scale, in: Encyclopedia of Hydrological Sciences, edited by: Anderson, M., John Wiley \& Sons, NY, 2005.
Smeck, N. E., Runge, E. C. A., and Mackintosh, E. E.: Dynamics and genetic modeling of soil systems, in: Pedogenesis and Soil Taxonomy, edited by: Wilding, L. P., Smeck, N. E., and Hall, G. F., Elsevier, New York, 51-81, 1983.

Stewart, J. B.: Modeling Surface Conductance of Pine Forest, Agr. Forest Meteorol., 43, 19-35, 1988.

Thompson, S. E., Harman, C. J., Troch, P. A., Brooks, P. D., and Sivapalan, M.: Spatial Scale Dependence of Ecohydrologically Mediated Water Balance Partitioning: A Synthesis Framework for Catchment Ecohydrology, Water Resour. Res., 47, W00J03, doi:10.1029/2010WR009998, 2011.

Thornthwaite, C. W. and Mather, J. R.: Instructions and tables for computing potential evapotranspiration and the water balance, Publ. Climatol., 10, 311, 1957.

Troch, P. A., Martinez, G. F., Pauwels, V. R. N., Durcik, M., Sivapalan, M., Harman, C., Brooks, P. D., Gupta, H., and Huxman, T.: Climate and vegetation water use efficiency at catchment scales, Hydrol. Process., 23, 2409-2414, doi:10.1002/Hyp.7358, 2009.

Volobuyev, V. R.: Ecology of Soils, Academy of Sciences of the Azerbaidzn SSR, Institute of Soil Science and Agrochemistry, Israel Program for Scientific Translations, Jersualem, 1964.

Volobuyev, V. R.: Thermodynamic Basis of Soil Classification, Soviet Soil Sci., 15, 71-83, 1983.

White, A. F. and Brantley, S. L.: Chemical weathering rates of silicate minerals: An overview, in: Chemical Weathering Rates of Silicate Minerals, Reviews in Mineralogy, Mineralogical Society of America, Washington, DC, 1-22, 1995.

White, D. A., Beadle, C. L., Sands, P. J., Worledge, D., and Honeysett, J. L.: Quantifying the effect of cumulative water stress on stomatal conductance of Eucalyptus globulus and Eucalyptus nitens: a phenomenological approach, Aust. J. Plant. Physiol., 26, 17-27, 1999.

Zehe, E., Blume, T., and Bloschl, G.: The principle of 'maximum energy dissipation': a novel thermodynamic perspective on rapid water flow in connected soil structures, Philos. T. Roy. Soc. B, 365, 1377-1386, doi:10.1098/rstb.2009.0308, 2010. 